Corrigendum

\title{
Corrigendum to "Overview on Topical 5-ALA Photodynamic Therapy Use for Non Melanoma Skin Cancers"
}

\author{
Carmen Cantisani $\mathbb{D}^{D}$, Giovanni Paolino, Valentina Faina $\mathbb{D}^{\mathbb{D}}$, Federica Frascani, \\ Franca Cantoresi, Daniela Bianchini, Gilda Fazia, and Stefano Calvieri
}

Department of Dermatology, "Sapienza" University of Rome, Policlinico Umberto I, Viale del Policlinico 15, 00186 Rome, Italy

Correspondence should be addressed to Carmen Cantisani; carmen.cantisani@uniroma1.it

Received 16 June 2019; Accepted 20 June 2019; Published 4 December 2019

Copyright (c) 2019 Carmen Cantisani et al. This is an open access article distributed under the Creative Commons Attribution License, which permits unrestricted use, distribution, and reproduction in any medium, provided the original work is properly cited.

The review article titled "Overview on Topical 5-ALA Photodynamic Therapy Use for Non Melanoma Skin Cancers" [1] contained wording from the following articles:

(i) In the section "20th Century Development of PDT", Wikipedia contributors, "Photodynamic therapy," Wikipedia, The Free Encyclopedia, https:// en.wikipedia.org/w/index.php?title=Photodynamic therapy\&oldid $=580645976$ (status at 7 November 7 , 2013). [2] (Not Cited)

(ii) Buinauskaite, Evelina, Rimantas Zalinkevicius, Jurate Buinauskiene, and Skaidra Valiukeviciene. "Pain during topical photodynamic therapy of actinic keratoses with 5-aminolevulinic acid and red light source: randomized controlled trial: pain during topical photodynamic therapy", Photodermatology Photoimmunology \& Photomedicine, 2013. doi:10.1111/phpp.12044. [3] (Not Cited)

(iii) Wiegell, S., Hædersdal, M., Philipsen, P., Eriksen, P., Enk, C. and Wulf, H. (2008), Continuous activation of PpIX by daylight is as effective as and less painful than conventional photodynamic therapy for actinic keratoses; a randomized, controlled, singleblinded study. British Journal of Dermatology, 158: 740-746. doi:10.1111/j.1365-2133.2008.08450.x. [4] (Cited as reference 26) (iv) Thanos SM, Halliday GM, Damian DL, Nicotinamide reduces photodynamic therapy-induced immunosuppression in humans. Br J Dermatol 2012; 167:631-6. doi:10.1111/j.1365-2133.2012.111 09.x. [5] (Not Cited)

(v) D'Orazio, John, Stuart Jarrett, Alexandra AmaroOrtiz, and Timothy Scott. "UV radiation and the skin", International Journal of Molecular Sciences, 2013. doi:10.3390/ijms140612222. [6] (Not Cited)

The article [1] includes an overlap of 1,255 words with Wikipedia contributors [2], 440 words with Buinauskaite et al. [3], 357 words with Wiegell et al. [4], 335 words with Thanos et al. [5], and 244 words with D'Orazio et al. [6].

\section{References}

[1] C. Cantisani, G. Paolino, V. Faina et al., "Overview on topical 5ALA photodynamic therapy use for non melanoma skin cancers," International Journal of Photoenergy, vol. 2014, Article ID 304862, 7 pages, 2014.

[2] Wikipedia contributors, “" Photodynamic therapy,” Wikipedia, The Free Encyclopedia," November 2013 https://en.wikipedia.org/w/ index.php?title=Photodynamic_therapy\&oldid $=580645976$.

[3] E. Buinauskaite, R. Zalinkevicius, J. Buinauskiene, and S. Valiukeviciene, "Pain during topical photodynamic therapy of actinic keratoses with 5-aminolevulinic acid and red light 
source: randomized controlled trial: pain during topical photodynamic therapy," Photodermatology Photoimmunology \& Photomedicine, vol. 29, no. 4, pp. 173-181, 2013.

[4] S. Wiegell, M. Hædersdal, P. Philipsen, P. Eriksen, C. Enk, and H. Wulf, "Continuous activation of PpIX by daylight is as effective as and less painful than conventional photodynamic therapy for actinic keratoses; a randomized, controlled, singleblinded study," British Journal of Dermatology, vol. 158, no. 4, pp. 740-746, 2008.

[5] S. M. Thanos, G. M. Halliday, and D. L. Damian, "Nicotinamide reduces photodynamic therapy-induced immunosuppression in humans," The British Journal of Dermatology, vol. 167, no. 3, pp. 631-636, 2012.

[6] J. D'Orazio, S. Jarrett, A. Amaro-Ortiz, and T. Scott, "UV radiation and the skin," International Journal of Molecular Sciences, vol. 14, no. 6, pp. 12222-12248, 2013. 

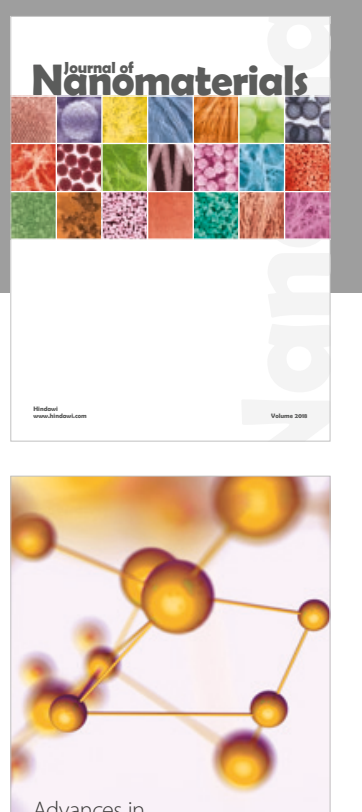

Physical Chemistry
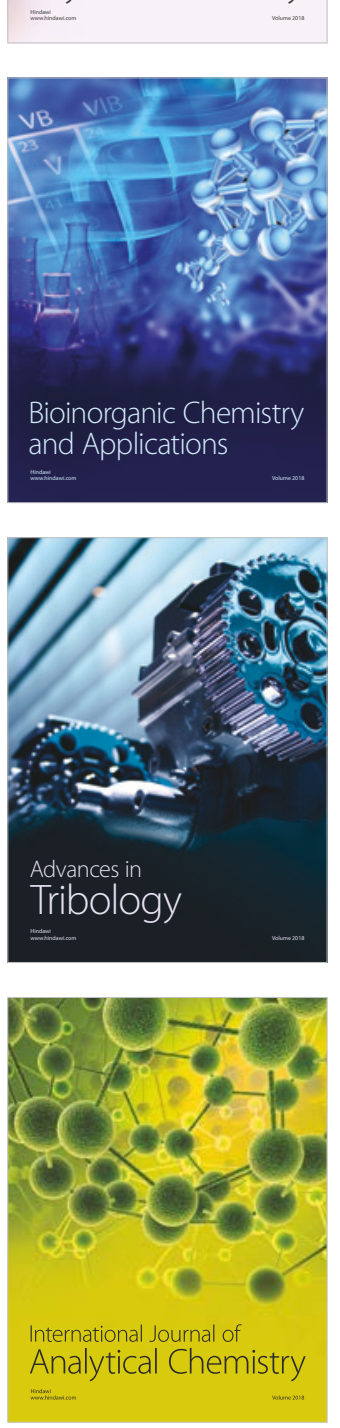

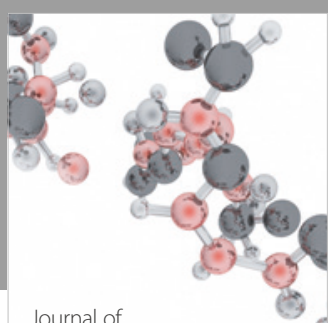

Analytical Methods

in Chemistry

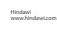

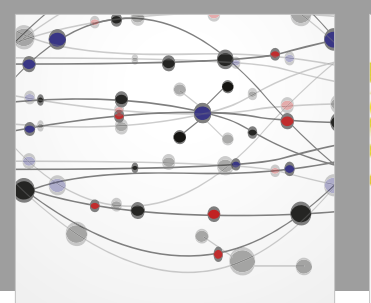

The Scientific World Journal

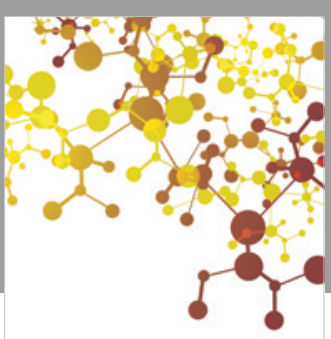

Journal of

Applied Chemistry
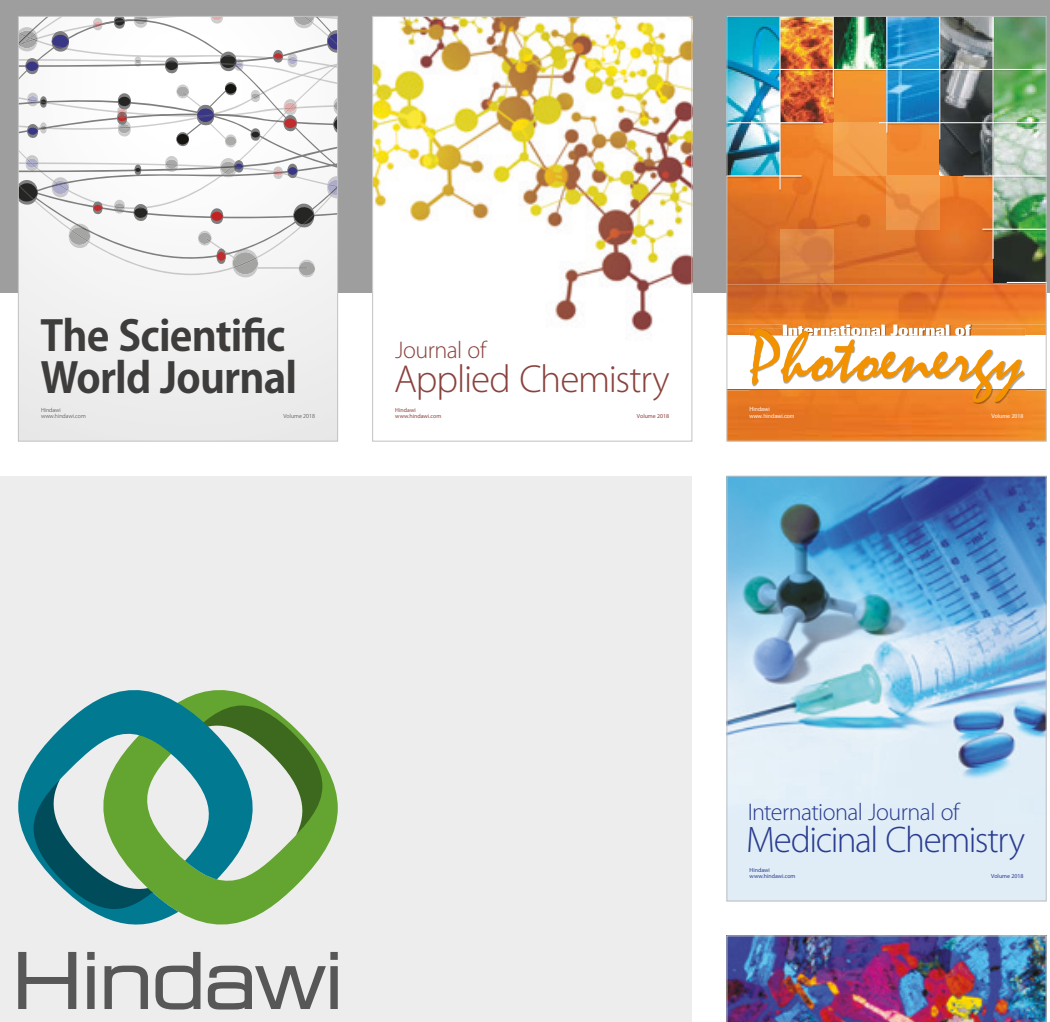

Submit your manuscripts at

www.hindawi.com
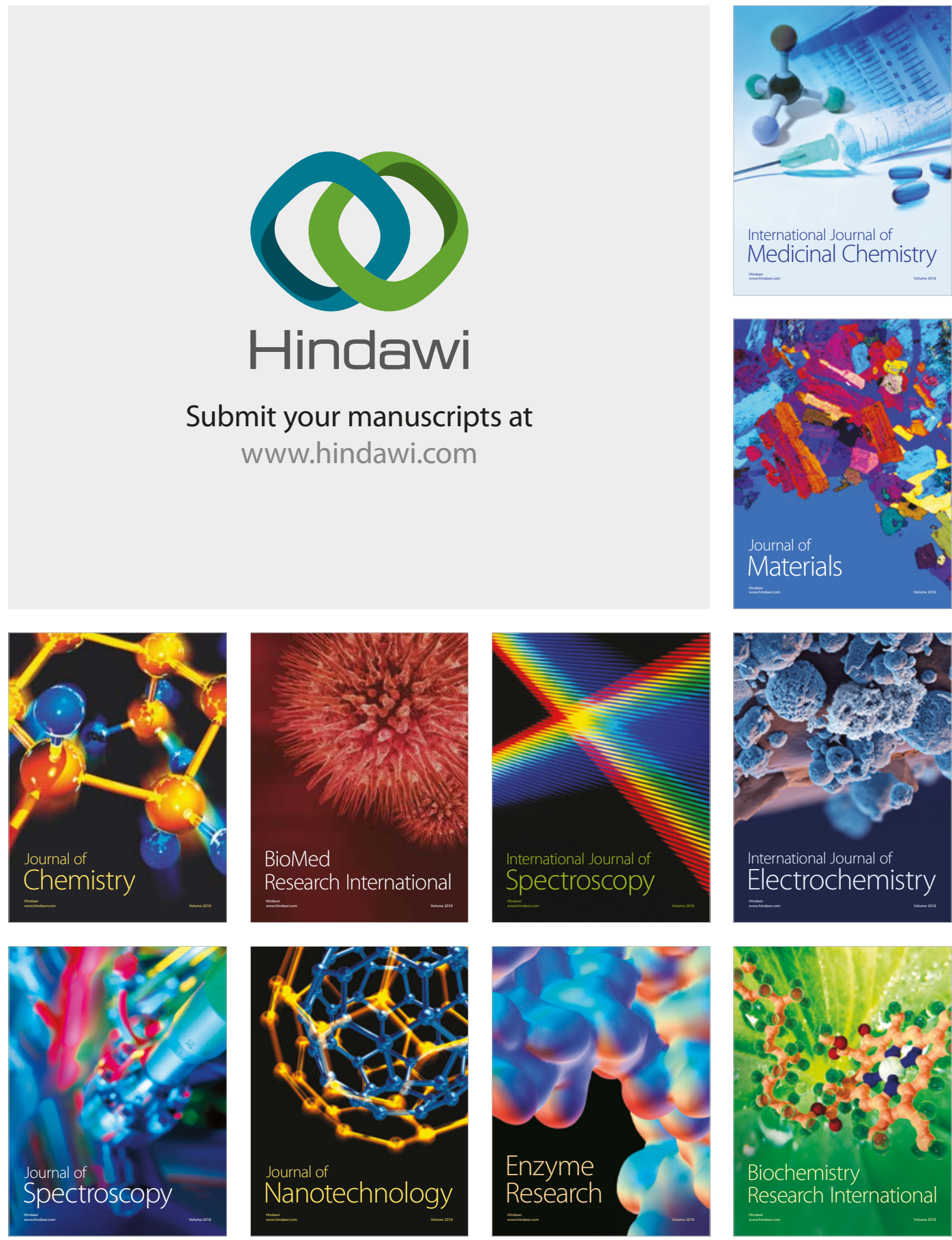
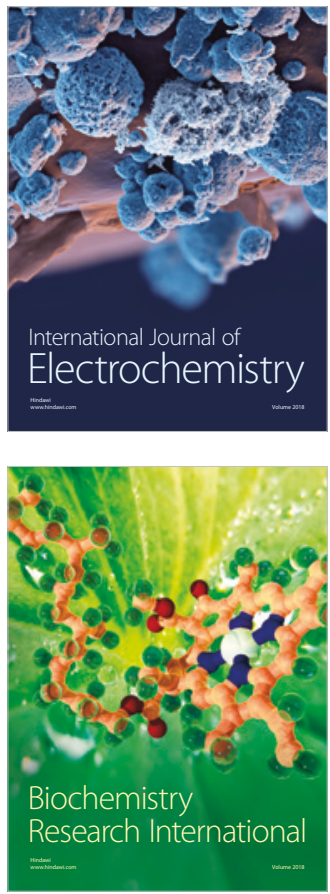